\title{
Existence of Coincidence Point for a Pair of Single-Valued and Multivalued Mappings
}

\author{
Pushpendra Semwal And R.C. Dimri
}

\begin{abstract}
In this paper we establish some results on the existence of coincidence point for multivalued Kannan maps using the concept of $w$-distance. Our results generalize and extend some well known results due to Latif and Albar [5] and others.
\end{abstract}

\section{Introduction And Preliminaries}

Using the concept of Hausdorff metric, many authers have proved fixed point and coincidence point results in the setting of metric spaces. Nadler [7] has used the concept of Hausdorff metric and obtained a multivalued version of the Banach contraction principle which states that each closed bounded valued contraction map on a complete metric space has a fixed point. On the other hand, Kannan [3] has proved an interesting fixed point result for singlevalued maps in the setting of metric spaces which is not an extension of the Banach contraction principle.Latif and Beg [4] have obtained a multivalued version of the Kannan's fixed point result.

In [2] Kada et al. have introduced a notion of $w$-distance on a metric space and improved several results replacing the involved metric by a generalized distance. While Suzuki [8] generalized Kannan's fixed point result under $w$-distance. Without using the concept of Hausedorff metric, most recently Feng and Liu [1] introduced a notion of multivalued contractive maps and proved a fixed point result extending Nadler's fixed point result concerning multivalued contractions. The aim of this paper is to obtain some results on the existence of coincidence points for multivalued $K_{w}$-maps with weak commutativity condition.

Throughout this paper, $X$ is a metric space with metric $d, C l(X)$ a collection of all nonempty closed subset of $X$. Consider a single-valued map $f: X \rightarrow X$ and a multivalued map $T: X \rightarrow 2^{X}$.

2010 Mathematics Subject Classification. Primary: 47H10, 46B20.

Key words and phrases. Coincidence point, multivalued mappings, $w$-distance, Kannan map. 
(a) An element $x \in X$ is called a coincidence point of $f$ and $T$ if $f(x) \in$ $T(x)$.

(b) $f$ is called Banach contraction if for a fixed constant $h \in(0,1)$ and for each $x, y \in X, d(f(x), f(y)) \leq d(x, y)$.

(c) $f$ is called Kannan contraction if for a fixed constant $r \in\left[0, \frac{1}{2}\right)$ and for each $x, y \in X, d(f(x), f(y)) \leq r[d(x, f(x))+d(y, f(y))]$. Clearly, Kannan contraction (which may not be continuous) is not a generalized of the Banach contraction principle. Kannan [3] has proved that each Kannan contraction self map on a complete metric space has a unique fixed point.

Definition $1([5])$. A map $\phi: X \rightarrow R$ is called lower semi-continuous if for any sequence $\left\{x_{n}\right\} \subset X$ with $x_{n} \rightarrow x \in X$ imply that $\phi(x) \leq$ $\liminf _{n \rightarrow \infty} \phi(x)$.

Definition 2 ([5]). A function $w: X \times X \rightarrow[0, \infty)$ is called $w$-distance on $X$ if it satisfies the following conditions;

$\left(w_{1}\right) w(x, z) \leq w(x, y)+w(y, z)$

$\left(w_{2}\right)$ a map $w(x,):. X \rightarrow[0, \infty)$ is lower semi-continuous;

$\left(w_{3}\right)$ for any $\epsilon>0$, there exists $\delta>0$ such that $w(z, x) \leq \delta$ and $w(z, y) \leq \delta$ imply $w(x, y) \leq \epsilon$ for any $x, y, z \in X$.

Definition $3([5])$. A multivalued map $T: X \rightarrow 2^{X}$ is $K_{w}$-map if there exists a nonnegative number $\mathrm{r} \in\left[0, \frac{1}{2}\right)$ and a $w$-distance function $w$ such that for any $x \in M, u \in T(x)$ there exists $v \in T(y)$ for all $y \in M$ such that

$$
w(u, v) \leq r\{w(x, u)+w(y, v)\} .
$$

Definition 4 ([6]). Let $T: X \rightarrow C l(X)$ be a multivalued map and $f: X \rightarrow$ $X$ a single-valued map such that $T(X) \subset f(X)$. Then $f$ and $T$ are said to be weakly commutative if $f(T(X)) \subset T(f(X))$ for all $x \in X$.

Lemma 1 ([5]). Let $X$ be a metric space with metric d let $w$ be a $w$-distance on $X$. Let $\left\{x_{n}\right\}$ and $\left\{y_{n}\right\}$ be sequences in $X$. Let $\left\{\alpha_{n}\right\}$ and $\left\{\beta_{n}\right\}$ be a sequences in $[0, \infty)$ converging to 0 , and let $x, y, z \in X$. Then the following hold:

(a) if $w\left(x_{n}, y\right) \leq \alpha_{n}$ and $w\left(x_{n}, z\right) \leq \beta_{n}$ for any $n \in N$, then $y=z$; in particular, if $w(x, y)=0$ and $w(x, z)=0$, then $y=z$;

(b) if $w\left(x_{n}, y_{n}\right) \leq \alpha_{n}$ and $w\left(x_{n}, z\right) \leq \beta_{n}$ for any $n \in N$, then $\left\{y_{n}\right\}$ converges to $z$;

(c) if $w\left(x_{n}, x_{m}\right) \leq \alpha_{n}$ for any $n, m \in N$ with $m>n$, then $\left\{x_{n}\right\}$ is a Cauchy sequence;

(d) if $w\left(y, x_{n}\right) \leq \alpha_{n}$ for any $n \in N$, then $\left\{x_{n}\right\}$ is a Cauchy sequence. 


\section{Main Results}

Theorem 1. Let $f: X \rightarrow X$ be a continuous function and let $T: X \rightarrow$ $C l(X)$ be a multivalued $K_{w}$ map such that if $f$ and $T$ are weakly commute and

$$
\inf w(x, u)+w(x, T(x)): x \in X>0
$$

for every $u \in X$ with $u \notin T(u)$. Then $f$ and $T$ has a coincidence point.

Proof. Let $x_{0} \in X$ be an arbitrary element of $X$ and let $y_{1}=f\left(x_{1}\right) \in T\left(x_{0}\right)$. Since $T$ is $K_{w}$-map, there exists $y_{2}=f\left(x_{2}\right) \in T\left(x_{1}\right)$ such that

$$
\begin{aligned}
w\left(y_{1}, y_{2}\right) & \leq r\left\{w\left(y_{1}, x_{0}\right)+w\left(y_{1}, y_{2}\right)\right\} \\
& \leq \frac{r}{1-r} w\left(y_{1}, x_{0}\right) ; \quad r \in\left[0, \frac{1}{2}\right) .
\end{aligned}
$$

Thus, we get a sequence $\left\{y_{n}\right\}$ in $X$ such that for every $n \in N, y_{n+1}=$ $f\left(x_{n+1}\right) \in T\left(x_{n}\right)$ and

$$
w\left(y_{n}, y_{n+1}\right) \leq\left(\frac{r}{1-r}\right) w\left(y_{n-1}, y_{n}\right)
$$

for some fixed $r, 0<r<\frac{1}{2}$. Note that for any $n \in N$, we have

$$
w\left(y_{n}, y_{n+1}\right) \leq\left(\frac{r}{1-r}\right)^{n} w\left(y_{1}, y_{0}\right) .
$$

Put $\lambda=\frac{r}{1-r}$. Then $0<r<1$. For $m$ and $n$ positive integers such that $m>n$, we have

$$
\begin{aligned}
w\left(y_{n}, y_{m}\right) & \leq w\left(y_{n}, y_{n+1}\right)+w\left(y_{n+1}, y_{n+2}\right)+\cdots+w\left(y_{m-1}, y_{m}\right) \\
& \leq \lambda^{n} w\left(y_{1}, x_{0}\right)+\lambda^{n+1} w\left(y_{1}, x_{0}\right)+\cdots+\lambda^{m-1} w\left(y_{1}, x_{0}\right) \\
& \leq \frac{\lambda^{n}}{1-\lambda} w\left(y_{1}, x_{0}\right),
\end{aligned}
$$

which implies that $w\left(y_{n}, y_{m}\right) \rightarrow 0$ as $n \rightarrow \infty$ and by Lemma $1\left\{y_{n}\right\}$ is a Cauchy sequence. From completeness of $X,\left\{y_{n}\right\}$ converges to some $v_{0} \in X$. Thus

$$
f\left(x_{n}\right) \rightarrow v_{0}
$$

Since $f$ is continuous,

Note that for each $n \geq 1$

$$
f\left(f\left(x_{n}\right)\right) \rightarrow f\left(v_{0}\right) .
$$

$$
f\left(x_{n}\right) \in T\left(x_{n-1}\right) .
$$

By weak commutativity of $f$ and $T$, we get

$$
f\left(f\left(x_{n}\right)\right) \in f\left(T\left(x_{n-1}\right)\right) \subseteq T\left(f\left(x_{n-1}\right)\right) .
$$

Hence

$$
f\left(v_{0}\right) \in T\left(v_{0}\right) .
$$


Let $n \in N$ be fixed. Since $\left\{y_{m}\right\}$ converges to some $v_{0}$ and $w\left(y_{n},.\right)$ is lower semi-continuous, we have

$$
w\left(y_{n}, v_{0}\right) \leq \lim _{m \rightarrow \infty} \inf w\left(y_{n}, y_{m}\right) \leq \frac{\lambda^{n}}{1-\lambda} w\left(y_{1}, x_{0}\right) .
$$

Therefore, as $n \rightarrow \infty$, we have $w\left(y_{n}, v_{0}\right)$. Assume that $f\left(v_{0}\right) \in T\left(\left(v_{0}\right)\right.$. Then, by hypothesis, we have

$$
\begin{aligned}
0 & <\inf \left\{w\left(y, v_{0}\right)+w(y, T(y)): y \in X\right\} \\
& \leq \inf \left\{w\left(y_{n}, v_{0}\right)+w\left(y_{n}, T\left(y_{n}\right)\right): n \in N\right\} \\
& \leq \inf \left\{w\left(y_{n}, v_{0}\right)+w\left(y_{n}, y_{n+1}\right): n \in N\right\} \\
& \leq \inf \left\{\frac{\lambda^{n}}{1-\lambda} w\left(y_{1}, x_{0}\right)+\lambda^{n} w\left(y_{1}, x_{0}\right): n \in N\right\}=0,
\end{aligned}
$$

which is impossible and hence $f\left(v_{0}\right) \in T\left(v_{0}\right)$.

Theorem 2. Let $f: X \rightarrow X$ be a continuous single-valued map and let $\left\{T_{n}\right\}$ be a sequence of multivalued maps from $X$ into $C l(X)$. Suppose there exists $0 \leq r<\frac{1}{2}$ such that for any two maps $T_{i}, T_{j} \in T_{n}, i \neq j$, and for any $x \in X, u \in T_{i}(x)$ there exists $v \in T_{j}(y)$ for all $y \in X$ with

$$
w(u, v) \leq r\{w(x, u)+w(y, v)\},
$$

and for each $n \geq 1$

$$
\inf \left\{w(x, u)+w\left(x, T_{n}(x)\right): x \in X\right\}>0 .
$$

for any $u \in T_{n}(u)$, and $f$ is weakly commuting with $\left\{T_{n}\right\}$ for every $n \in N$. Then $f$ and $\left\{T_{n}\right\}_{n \in N}$ has a coincidence point.

Proof. Let $x_{0}$ be an arbitrary element of $X$ and let $y_{1}=f\left(x_{1}\right) \in T_{1}\left(x_{0}\right)$. Then there is an element $y_{2}=f\left(x_{2}\right) \in T_{2}\left(x_{1}\right)$ such that

$$
w\left(y_{1}, y_{2}\right) \leq \frac{r}{1-r} w\left(y_{1}, x_{0}\right) .
$$

So, there exists a sequence $\left\{y_{n}\right\}$ such that $y_{n+1}=f\left(x_{n+1}\right) \in T_{n+1}\left(x_{n}\right)$ for every $n \geq 1$,

$$
w\left(y_{n}, y_{n+1}\right) \leq\left(\frac{r}{1-r}\right)^{n} w\left(y_{1}, x_{0}\right) .
$$

Put $\lambda=\frac{r}{1-r}$. Note that $0<\lambda<1$ and

$$
w\left(y_{n}, y_{n+1}\right) \leq \lambda^{n} w\left(y_{1}, x_{0}\right)
$$

for all $n \geq 1$. Then as $n \rightarrow \infty,\left\{y_{n}\right\}$ is a Cauchy sequence in $X$. By completeness of $X, y_{n} \rightarrow p \in X$ i.e., $f\left(x_{n}\right) \rightarrow p$.

By continuity of $f$

$$
f\left(f\left(x_{n}\right)\right) \rightarrow f(p)
$$

and

$$
f\left(x_{n}\right) \in T_{n}\left(x_{n-1}\right)
$$


By weak commutativity of $f$ and $T_{n}$ for every $n$,

$$
f\left(f\left(x_{n}\right)\right) \in f\left(T_{n}\left(x_{n-1}\right)\right) \subset T_{n}\left(f\left(x_{n-1}\right)\right) .
$$

Since $\left\{y_{n}\right\}$ converges to $p$ and $w\left(y_{n},.\right)$ is lower semi-continuous, following the proof of Theorem 1 we obtain

$$
w\left(y_{n}, p\right) \leq \lim _{m \rightarrow \infty} \inf w\left(y_{n}, y_{m}\right) \leq \frac{\lambda^{n}}{a-\lambda} w\left(y_{1}, x_{0}\right),
$$

which converges to 0 as $n \rightarrow \infty$. Now assume that $p \in T_{m}(p)$. Then by hypothesis, and for $n>m$ and $m \geq 1$ we have

$$
\begin{aligned}
0 & <\inf \left\{w(y, p)+w\left(y, T_{m}(x)\right): x \in X\right\} \\
& \leq \inf \left\{w\left(y_{m-1}, p\right)+w\left(y_{m-1}, T_{m}\left(x_{m-1}\right)\right): m \in N\right\} \\
& \leq \inf \left\{w\left(y_{m-1}, p\right)+w\left(y_{m-1}, y_{m}\right): m \in N\right\} \\
& \leq \inf \left\{\frac{\lambda^{m-1}}{1-\lambda} w\left(y_{1}, x_{0}\right)+\lambda^{m-1} w\left(y_{1}, x_{0}\right): m \in N\right\}=0,
\end{aligned}
$$

which is not possible.

Therefore $f(p) \in T_{m}(p)$. But $T_{m}$ is arbitrary, hence $p$ is a coincidence point of $f$ and $\left\{T_{n}\right\}_{n \in N}$.

Example 1. Let $X=[0,1]$ be a metric space with $w$-distance function $w: X \times X \rightarrow[0, \infty)$ defind by $w(x, y)=\sqrt{\left(x^{2}+y^{2}\right)}$ and let

$$
\begin{gathered}
T(x)= \begin{cases}{\left[0, \frac{1}{2}\right],} & x \in\left[0, \frac{1}{2}\right] ; \\
1-x, & x \in\left(\frac{1}{2}, 1\right] ;\end{cases} \\
f(x)=\frac{x}{2}, \quad x \in[0,1] .
\end{gathered}
$$

Since $f$ and $T$ are weakly commutative and satisfies all the conditions of Theorem 1. Then for $x=\frac{1}{2}$

$$
f\left(\frac{1}{2}\right)=\frac{1}{4}
$$

and

$$
T\left(\frac{1}{2}\right)=\left[0, \frac{1}{2}\right] .
$$

Therefore $f\left(\frac{1}{2}\right) \in T\left(\frac{1}{2}\right)$. Hence $\frac{1}{2}$ is a coincidence point of $f$ and $T$ in $X$. Similarly, all points from $\left[0, \frac{1}{2}\right]$ are coincidence points of $f$ and $T$ in $X$.

\section{REFERENCES}

[1] Y. Feng and S. Liu, Fixed point theorem for multivalued contractive mappings and multivalued Caristi type mappings, J. Math. Anal. Appl. 317 (2006), 103-112.

[2] O. Kada, T. Suzuki and W. Takahashi, Nonconvex minimization theorems and fixed point theorems in complete metric spaces, Math. Japon. 44 (1996), 381-391.

[3] R. Kannan, Some results on fixed points, Bull. math. Calcutta. 6 (1968), 405-408. 
[4] A. Latif and I. Beg, Geometric fixed point for single and multivalued mappings, Demonstratio Mathematica 30(4), (1997),791-800.

[5] A. Latif and W.A. Albar, Fixed point results for multivalued maps, Int. J. Contemp. Math. Sciences, 2(23) (2007), 1129-1136.

[6] A. Latif and A.E. AL-Mazrooei, Coincidence points for contraction type maps, Acta Math. Uni. Comeni LXXVII (2) (2008), 175-180.

[7] S.B. Nadler, Multivalued contraction mappings, Paciffic J. Math. 30 (1969), 475-488.

[8] T. Suzuki, Several fixed point theorems in complete metric spaces, Yokohama Math. J. 44 (1997), 61-72.

Pushrendra Semwal

Department of Mathematics

H.N.B. Garhwal University

Srinagar Garhwal

INDIA

E-mail address: psrsdm@gmail.com

\section{R.C. DimRi}

Department of Mathematics

H.N.B. Garhwal University

SRinagar Garhwal

INDIA

E-mail address: dimrirc@gmail.com 